Int. J. Electrochem. Sci., 13 (2018) 12188 - 12207

International Journal of

ELECTROCHEMICAL

SCIENCE

www.electrochemsci.org

\title{
Coffee Husk as Corrosion Inhibitor for Mild Steel in HCl Media
}

\author{
Renata F. B. Cordeiro ${ }^{1, *}$, Allan J. S. Belati ${ }^{1}$, Daniel Perrone ${ }^{2}$, Eliane D'Elia ${ }^{1}$ \\ ${ }^{1}$ Department of Inorganic Chemistry, Chemistry Institute, Federal University of Rio de Janeiro, Brazil \\ ${ }^{2}$ Laboratory of Nutritional Biochemistry and Food, Department of Biochemistry, Chemistry Institute, \\ Federal University of Rio de Janeiro, Brazil \\ *E-mail: rfbcordeiro@gmail.com
}

doi: $10.20964 / 2018.12 .29$

Received: 7 August 2018 / Accepted: 19 September 2018 / Published: 5 November 2018

The corrosion inhibition of mild steel by coffee husk aqueous extract (1) and its high molecular weight fraction (2) was investigated in $1 \mathrm{~mol} \mathrm{~L}^{-1} \mathrm{HCl}$ medium. Gravimetric tests showed that for both inhibitors, inhibition efficiency (IE) increased with time and extract concentration, reaching a $I E$ of $89.2 \%$ and $90.3 \%$ for $800 \mathrm{mg} \mathrm{L}^{-1}$ of inhibitors (1) and (2), respectively, in $24 \mathrm{~h}$ of immersion. Gravimetric tests varying temperature showed the activation energy $\left(E_{a}\right)$ barely varied for Inhibitor 1 . For Inhibitor 2 a decrease in $E_{a}$ was noted, a hint it is attached on the metal surface by chemisorption. Polarization curves indicated that both extracts act as mixed type inhibitors. Impedance results showed a decrease in double layer capacitance $\left(C_{d l}\right)$ and an increase in charge transfer resistance $\left(R_{c t}\right)$, with a better performance for inhibitor (2). Both extracts presented a good linearity with respect to Langmuir isotherm, an evidence of a monolayer formation. Our results suggest inhibitor 1 acts by purely blocking the metal surface, and in case of inhibitor 2, it screens the metal surface and reduces the activation energy.

Keywords: Mild steel, corrosion inhibitor, coffee husk, waste, natural products.

\section{$\underline{\text { FULL TEXT }}$}

(C) 2018 The Authors. Published by ESG (www.electrochemsci.org). This article is an open access article distributed under the terms and conditions of the Creative Commons Attribution license (http://creativecommons.org/licenses/by/4.0/). 